\title{
Mapping citizen science contributions to the UN sustainable development goals
}

\author{
Dilek Fraisl ${ }^{1,2}$ (1) $\cdot$ Jillian Campbell $^{3} \cdot$ Linda See $^{1} \cdot$ Uta Wehn $^{4} \cdot$ Jessica Wardlaw ${ }^{5} \cdot$ Margaret Gold $^{6} \cdot$ Inian Moorthy $^{1}$. \\ Rosa Arias $^{7}$. Jaume Piera ${ }^{8}$. Jessica L. Oliver ${ }^{9,10}$. Joan Masó ${ }^{11}$. Marianne Penker ${ }^{2}$. Steffen Fritz ${ }^{1}$
}

Received: 4 November 2019 / Accepted: 14 June 2020 / Published online: 2 July 2020

(c) The Author(s) 2020

\begin{abstract}
The UN Sustainable Development Goals (SDGs) are a vision for achieving a sustainable future. Reliable, timely, comprehensive, and consistent data are critical for measuring progress towards, and ultimately achieving, the SDGs. Data from citizen science represent one new source of data that could be used for SDG reporting and monitoring. However, information is still lacking regarding the current and potential contributions of citizen science to the SDG indicator framework. Through a systematic review of the metadata and work plans of the 244 SDG indicators, as well as the identification of past and ongoing citizen science initiatives that could directly or indirectly provide data for these indicators, this paper presents an overview of where citizen science is already contributing and could contribute data to the SDG indicator framework. The results demonstrate that citizen science is "already contributing" to the monitoring of 5 SDG indicators, and that citizen science "could contribute" to 76 indicators, which, together, equates to around 33\%. Our analysis also shows that the greatest inputs from citizen science to the SDG framework relate to SDG 15 Life on Land, SDG 11 Sustainable Cities and Communities, SDG 3 Good Health and Wellbeing, and SDG 6 Clean Water and Sanitation. Realizing the full potential of citizen science requires demonstrating its value in the global data ecosystem, building partnerships around citizen science data to accelerate SDG progress, and leveraging investments to enhance its use and impact.
\end{abstract}

Keywords Sustainable Development Goals (SDGs) · Citizen science · SDG indicators · Tier classification for SDG indicators $\cdot$ Crowdsourcing $\cdot$ Community-based monitoring

\section{Introduction}

In September 2015, the United Nations Sustainable Development Summit adopted an international framework to guide global development efforts, entitled 'Transforming our world: the 2030 Agenda for sustainable development' (UN 2015). The Agenda includes 17 Sustainable Development Goals (SDGs) and 169 targets relating to global challenges including poverty, inequality, climate, environmental degradation, prosperity, and peace and justice. The UN General

Handled by Yuya Kajikawa, Tokyo Institute of Technology, Japan.

Electronic supplementary material The online version of this article (https://doi.org/10.1007/s11625-020-00833-7) contains supplementary material, which is available to authorized users.

Dilek Fraisl

fraisl@iiasa.ac.at

Extended author information available on the last page of the article
Assembly tasked a group of technical and statistical experts with developing a global monitoring framework that would allow the tracking of each SDG target, while at the same time keeping in mind the feasibility and reporting burden of such a monitoring framework. This led to the creation and adoption of the current list of 244 SDG indicators by the UN General Assembly (UN 2017).

The SDG indicator framework is developed based on the existence of a global methodology and data availability. Each SDG indicator was placed into one of three tiers to track progress towards operationalizing the indicator framework. A simplification of the tiering framework is: Tier I: existence of an agreed methodology and good data coverage (at least 50\%); Tier II: agreed methodology, but data are lacking (less than 50\% data coverage), and Tier III: no established methodology (UN n.d.). The monitoring of the SDGs is expected to happen at the subnational, national, regional, and global level to ensure the vertical coherence of policies and actions. In terms 
of official reporting, national governments have the primary responsibility for monitoring the SDG indicators (UN 2017). Each SDG indicator has one or more custodians, who are responsible for (i) developing the global methodology based on the best available science, research, and data expertise, and (ii) identifying the data sources that can contribute to the SDG indicator. Custodians are typically a UN agency or other international organization, who additionally ensure that the methodology is applicable to all countries, regardless of their level of development. National data are expected to be used to populate the official reports of countries on SDG progress (known as Voluntary National Reviews on the SDGs). National data then feed into the UN global database on the SDGs, which is used to analyze regional and global progress, including through an annual report by the Secretary General on the SDGs (UN 2019a). The custodian agency is also responsible for adjusting the data when required to ensure comparability, and for developing techniques to fill data gaps. Since the adoption of the SDG indicator framework, there has been an effort to upscale statistical methodological work and data collection across the SDG indicators. For example, of the SDG indicators that are not related to the environment, only $7 \%$ remained Tier III, compared to the $28 \%$ that were Tier III at the adoption of the SDG indicators. On the other hand, $26 \%$ of the environment-related SDG indicators remained Tier III as of July 2019 (UN 2019 b, c, n.d.), and a further $32 \%$ have insufficient data available for global tracking (UN Environment 2019).

The funding required to measure all 244 SDG indicators using only traditional data sources creates a barrier for countries to monitor and assess progress toward the SDGs, particularly for developing countries (IAEG Secretariat 2014). Effective and efficient monitoring of the SDGs will require better utilization of new data sources and data techniques (Daguitan et al. 2019a, b). For example, the role of Earth Observation (EO) in addressing societal challenges and supporting the implementation of the 2030 Agenda has been long recognized by governments, industry, and scientific institutions (GEO 2017). EO is a source of data that could help to harmonize information on natural resources, ecosystems, and environmental issues via remote sensing technologies and in-situ measurements (OECD 2017). A number of studies have been conducted by the EO community that aim to define the concrete contributions of EO data in measuring progress towards the SDGs (GEO 2017; CEOS 2018). One such study was jointly conducted, for example, by the Group on Earth Observation (GEO), which is an intergovernmental partnership that improves the availability, access, and use of EO data (GEO 2018), and the Committee on Earth Observation Satellites (CEOS), which is an international consortium involved in the management of international and civil spaceborne missions for observing the Earth (CEOS 2015). Their analysis revealed that 29 SDG indicators could be monitored using EO data, and EO could provide support for the achievement of around 71 targets (CEOS 2018).

Official statistics have typically been based on data that are officially collected by national governments (e.g., through surveys, censuses, official sensors) (Daguitan et al. 2019a, b). To date, citizen science methodologies and data are not included in SDG data acquisition. However, doing so may provide data at finer spatial and temporal scales than would otherwise be possible to obtain since data from citizen science are often collected at higher frequencies than the traditional sources of data used as inputs to the SDG indicators, as well as in a spatially disaggregated way. Citizen science, as a concept, has diverse definitions, terms, and interpretations, where no single term or definition is suitable for all contexts (Eitzel et al. 2017). In the scope of our work, we take an all-encompassing approach and define citizen science using three main characteristics: "public participation", "voluntary contributions", and "knowledge production" (SDSN TReNDS 2019). Our use of the term citizen science most closely aligns with the concept of "Public Participation in Scientific Research (PPSR)", which Shirk et al. (2012) describe as "intentional collaborations in which members of the public engage in the process of research to generate new science-based knowledge". PPSR encompasses projects with five degrees of participation. This includes: (i) contractual projects (where communities approach researchers to conduct a scientific investigation on a particular issue); (ii) contributory projects (usually designed by scientists, and volunteers are involved mainly to contribute data); (iii) collaborative projects (usually designed by scientists and volunteers are involved to contribute data, but also support project design, data analysis, and/or dissemination of results); (iv) co-created projects (designed by scientists and volunteers together, and volunteers are actively involved in most or all aspects of the research) and (v) collegial projects (volunteers conduct research independently expecting different degrees of recognition by professionals) (Shirk et al. 2012). As with PPSR, we have elected to include a wide range of diverse projects from hypothesis-driven science to practices that involve local knowledge and observations for addressing the political and social issues that communities face. Our broad interpretation of citizen science includes any initiative that produces scientific knowledge through the participation of volunteers, such as community-based monitoring (Conrad and Hilchey 2011), community-based participatory research (Asaba and Suarez-Balcazar 2018), participatory action research (MacDonald 2012), citizen-generated data (Datashift 2017), crowdsourcing (Howe 2006; Nov et al. 2010), volunteered geographic information (Sieber and Haklay 2015), and participatory sensing (Coulson et al. 2018), among others. 
In the past, there has been research that has proposed the value of including citizen science data in the SDG reporting process (IAEG Secretariat 2014; Flückiger and Seth 2016; Fritz et al. 2019). However, there is currently a lack of comprehensive research that provides systematic evidence regarding where citizen science currently contributes or where it could potentially contribute to the SDGs at an indicator level. The most relevant piece of work to date was undertaken by West and Pateman (2017), who outlined how citizen science approaches could contribute to the definition, monitoring, and/or implementation of the SDGs. In total, they identified 42 of the 169 targets to which citizen science could contribute, but they did not consider the indicator level, nor did they present examples of initiatives to support these suggestions based on a systematic review. Another study by the European Commission, which undertook an inventory of citizen science projects for environmental policies, focused on the goal level (Bio Innovation Service 2018). The results showed that the 503 environmental citizen science initiatives included in the inventory could contribute to all 17 goals, directly or indirectly. In the scope of their work, direct contribution means that the "project aim fits an SDG", while indirect contribution describes projects that "may contribute to fulfilling an SDG, as a by-product of its activities". For example, SDG 4 Quality Education, SDG 9 Industry, Innovation and Infrastructure, and SDG 16 Peace, Justice and Strong Institutions are covered by all the projects listed in the inventory, at least indirectly. SDG 3 Good Health and Wellbeing, SDG 13 Climate Action, SDG 15 Life on Land, and SDG 17 Partnerships for the Goals were covered by the majority of the projects $(78 \%, 86 \%, 75 \%$, and 52\%, respectively), both directly and indirectly. SDG 14 Life below Water and SDG 15 Life on Land had the highest direct contributions (18\% and 58\%, respectively). What is currently missing is an understanding of which SDG indicators citizen science is already contributing to and where its future potential lies. Hence, the aim of this paper is to provide a systematic review of how citizen science data generated by volunteers can provide data for the SDG indicators. This includes filling information gaps at the national level or complementing national level information through improved timeliness or reporting at a higher spatial resolution. As SDG reporting relies on national data compilation by national statistical systems, this paper additionally provides a discussion on the opportunities and challenges for bringing citizen science into the scope of national official statistics.

\section{Methodology}

To systematically analyse which SDG indicators citizen science is already contributing to and where its potential lies in the future, the methodology consists of two main parts. The first part involved reviewing each SDG indicator to identify whether citizen science (i) is currently contributing data to an indicator, (ii) could contribute in the future, or (iii) has no foreseen contribution at present. The second part of the methodology involved summarizing the results of the indicator review in order to understand the current landscape of citizen science contributions to the SDGs.

\section{Systematic review of the SDG indicators}

The SDG indicator review process was comprised of a number of steps (Fig. 1). Step 1 was to compile a list of all SDG indicators (see Table S1 in the Supplementary Material for the complete list), which was downloaded from the UN Statistics Division website on 13 April 2019. Step 2 was to consult the metadata documents of the indicators that describe the methodology and data sources associated with each indicator (https://unstats.un.org/sdgs/metadata/). This provided us with an understanding of the current stage of

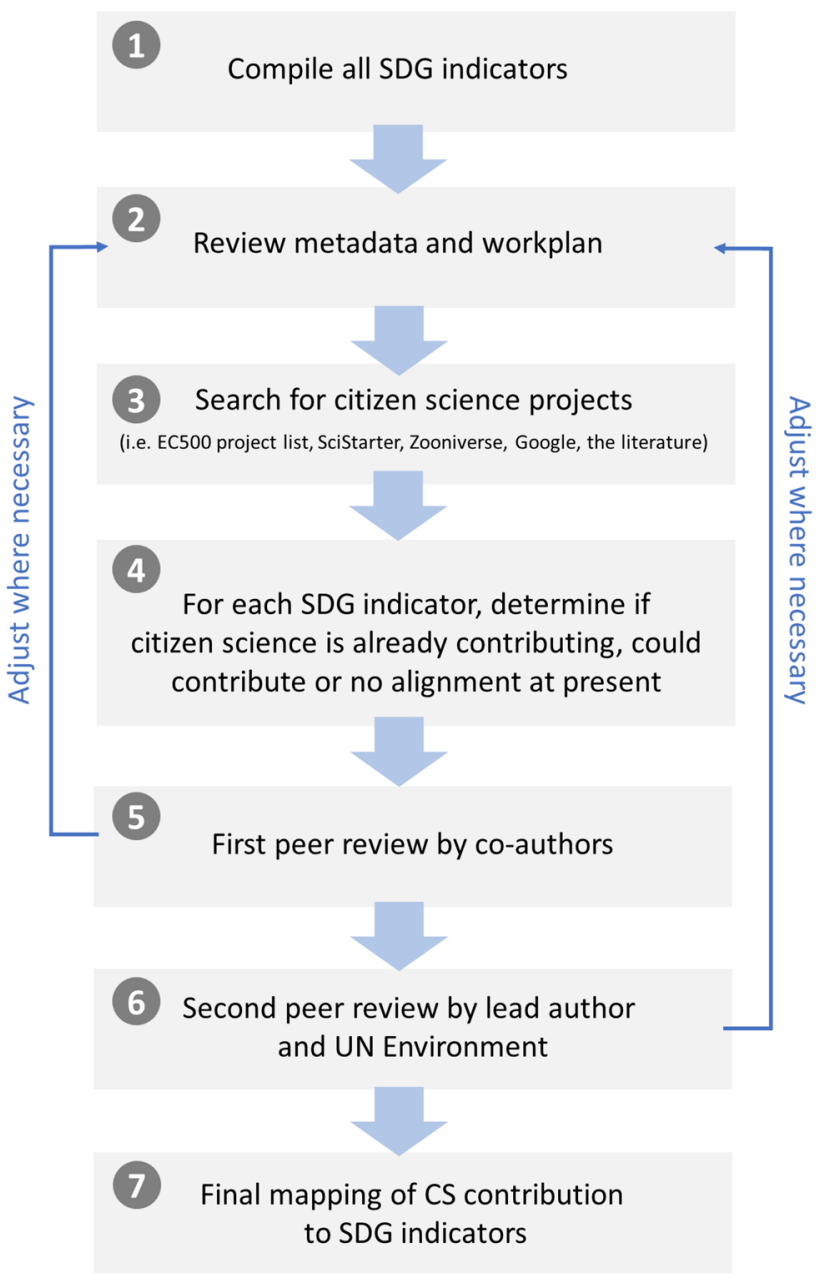

Fig. 1 Methodology for the systematic review of the SDG indicators for citizen science 
methodological development of the indicators (i.e., Tier I, II or III), what the methodology for the indicator is (if it exists), what data are needed to calculate the indicator (if already decided), and the source of the input data. For cases where there was no metadata or work plan, which occurred for a few of the indicators, the analysis was a judgement based on the indicator title.

Step 3 involved identifying citizen science projects to provide a strategic overview on relevant citizen science initiatives that capture the breadth of different types of projects relevant to each indicator, which was completed using the following procedure:

(i) Reviewed the Inventory of citizen science projects for environmental policies, which was undertaken as part of a study commissioned by the European Commission (Bio Innovation Service 2018), (https://data.jrc. ec.europa.eu/dataset/jrc-citsci-10004);

(ii) Queried SciStarter, an online database of citizen science projects from around the world, using respective indicator-relevant keywords (https://scistarter.org/);

(iii) Reviewed Zooniverse, an online platform that hosts over 100 virtual citizen science projects from around the world, by respective indicator-relevant topics (https://www.zooniverse.org/);

(iv) Queried the Google internet search engine, using keywords from respective indicators and combinations of 'citizen science', 'community-based monitoring', 'crowdsourcing', etc. (https://google.com);

(v) Queried Scopus, an online database for peer-reviewed citations and abstracts, using the same keywords as those listed in the Google queries (https://www2. scopus.com/); and

(vi) Used contributions from the co-authors based on their extensive local, regional, and global knowledge of citizen science initiatives and projects.

As mentioned in the introduction, we use citizen science in a broad sense in this paper to include public participation, voluntary contributions and knowledge production (SDSN TReNDS 2019). Hence, the initiatives that fall within this definition were included, even if they do not explicitly use the term citizen science. Regarding public participation, our approach integrates the five models on degree of participation from Shirk et al. (2012), which includes, but is not limited to, projects where members of the public primarily contribute data (at one end of the spectrum) to designing the research together with professional scientists and active involvement in most or all phases of the research (at the other end of the spectrum) (Shirk et al. 2012). Regarding voluntary contributions, our experience is that the term voluntary has different meanings in different contexts. For example, in the context of community-based monitoring activities in the health domain, the terms Community Health Workers $(\mathrm{CHWs})$ or Volunteers are widely used, and are defined as the first point of contact between communities and the health system, usually in low- or middle-income countries. CHWs are trained to provide a specific function, having no formal professional qualifications. They can be employed and salaried by government organizations, nongovernmental organizations (NGOs), or perform entirely on a voluntary basis. They may receive different forms of incentives, ranging from uniforms or one-time financial incentives related to health insurance (Ormel et al. 2019). This makes it difficult to determine whether a community-based monitoring program involving CHWs is voluntary or whether they were paid salaries. In our mapping, we did not include projects where participants were paid salaries, but did include examples where participants received small incentives. We excluded those cases from our mapping where we could not be sure about the incentives provided to participants. Finally, in the scope of our study, knowledge production refers to investigation, monitoring, or scientific research as suggested by Eitzel et al. (2017).

Step 4 involved determining the category for the indicator from the following three choices:

(i) already contributing, which means that data from at least one citizen science project are already used for reporting on a specific SDG indicator at the national or global level;

(ii) could contribute, where data from at least one citizen science project could be used for a specific SDG indicator, but are not used so far and the project and/ or data requirements might need modification/adaptation before the resulting data can be used (provided this modification is feasible); and

(iii) no alignment at present.

When a project was found to relate to an indicator topic (step 3), it was then assigned to either "already contributing" to that indicator or "could contribute". Assignment to the category "currently contributing" involved finding evidence in documents, websites, and in the literature. If the evidence was not present in documents, but a contribution to an indicator was thought to be the case, project staff, custodian agencies, or other organizations involved in reporting efforts for that particular indicator, such as Birdlife International, were consulted to provide the evidence for these contributions. These indicators were then further classified into "direct contributions" or "supplementary contributions". Direct contributions mean that citizen science data are already contributing or could contribute to the calculation of the official SDG indicator. This would include indicators that could utilize citizen science data as the primary data source (e.g., bird species prevalence can be 
primarily based on citizen science data from bird watchers) or indicators where citizen science is part of the indicator or used to fill spatial or temporal gaps in data (e.g., air quality reference stations can be coupled with citizen science data on air quality). In the context of this paper, a supplementary contribution means that citizen science data could provide information that is useful to contextualize an SDG indicator or target. For example, the official SDG indicator on poverty aims to capture income poverty, but citizen science data covering the quality of housing or furnishings in homes (e.g., Dollar Street) provide supplementary information that can be used to better understand poverty. If no evidence of a direct contribution could be found but a project was thought to be producing the types of data or similar data to those required by the indicator, then the project was assigned to the category "could contribute". We note that some of the projects that we identified as "could contribute" may not be collecting the exact data that are needed for the indicator. However, we added them to our mapping as they have great potential to support the indicator if they could be extended to collect the specific data required for the indicator (e.g., through modifications to their data collection protocol). As an example, the Engage TB and One Impact projects could provide supplementary data for indicator 3.3.2 Tuberculosis incidence per 100,000 population. Our suggestion is that, if designed accordingly, they or other similar projects could also support data collection for the HIV-related indicator 3.3.1 Number of new HIV infections per 1,000 uninfected population, by sex, age and key populations. Finally, if no projects were found or the indicator was based on data that were not amenable to collection by citizens, then that indicator was categorized as "no alignment at present".

Note that we did not consider the robustness of the quality procedures used in the citizen science projects listed in Table S1. Instead, we only considered whether projects are already contributing (where high quality can be assumed) or where they could potentially contribute (where data quality protocols would require compliance if the data were to be used for SDG reporting in the future).

Once the full set of indicators was reviewed, then the first peer review process began in step 5. Each co-author was assigned a different set of indicators to those they initially reviewed to peer review the work of others. This involved reading the metadata for the indicator (step 2), reviewing the category chosen (during step 4), searching the five sources (step 3) and modifying the category of SDG contribution as appropriate. If a citizen science project was listed as contributing to an indicator, the evidence for this claim was reviewed. In the majority of cases, there was consensus. However, two situations of disagreement arose during this process: (i) the peer reviewer identified citizen science projects that were not found by the original reviewer; and (ii) there was disagreement between the original reviewer and the peer reviewer regarding whether a project was considered suitable for a particular indicator. In the first situation, any new citizen science projects identified were discussed between the two reviewers to reach consensus. As this constituted an omission error, consensus was straightforward. The second situation arose because reviewers have different experiences of citizen science that influence their definition of citizen science as a concept. In this situation, reviewers were asked to use the definition of citizen science as set out in the paper and flag any remaining disagreements. The lead author then reviewed any situations with outstanding disagreements in step 6 .

Once step 5 was completed, a second peer review process was undertaken (step 6) in two phases. In the first phase of step 6, the lead author of this paper reviewed the mapping done by all other co-authors to ensure that the metadata had been interpreted correctly and to modify those indicators that were initially mapped as having "no alignment", changing them to "could contribute" where needed, due to additional searching and knowledge of potential initiatives. The lead author also addressed any outstanding disagreements between the reviewer and the peer reviewer identified in step 5. This involved reviewing all the projects identified and all the evidence provided, and then applying the definition of citizen science outlined in the paper to determine whether the citizen science projects are applicable. A final discussion between the lead author, the reviewer and the peer reviewer was then held to reach consensus.

The second phase of step 6 involved a review of all indicators by the chief statistician of UN Environment, who works on the development of the environmental SDG indicators for which UN Environment is a custodian agency. Once again, in the majority of cases, there was consensus between the lead author and the chief statistician, but two situations of disagreement arose. The first case was similar to the situation described above, i.e., disagreements regarding whether a project was citizen science or not, e.g., self-reporting or community-based monitoring, which falls within the definition of citizen science. These disagreements were discussed until consensus was reached. The second situation was similar but occurred when consensus could not be reached, in particular for those SDGs for which UN Environment is not the custodian agency; the chief statistician, therefore, did not have the required expertise. The lead author then contacted other custodian agencies such as the World Bank, UNODC (UN Office on Drugs and Crime), UN FAO (the Food and Agriculture Organization of the UN) and WHO (World Health Organization) for relevant indicators.

In the steps described above, the co-authors have not applied a formal consensus building method or approach over disagreements, but rather encouraged discussions among the reviewers, which allowed different viewpoints and alternative explanations to be introduced, debated, 
broken down and reassessed. In this way, the authors were able to collectively analyze and evaluate the reasoning and results of others that, in the majority of cases, led to a convergence in reviewers' perceptions. In three cases, the authors could not reach consensus due to the limited expertise in the particular thematic area of a specific indicator so the authors agreed to leave the judgement to the responsible staff at the relevant custodian agency/ies. This was identified as the best possible resolution to a few minor disagreements among the authors, since custodian agencies are responsible for defining the methodologies of the relevant indicators, including their sources of information and data collection methods, and also have accountability for quality and accuracy of reporting at the global level. In these cases, the lead author consulted the relevant staff members of the custodian agencies and presented the views of different authors to identify the accurate mapping and justification. For example, SDG indicator 16.1.3 is about the proportion of population subjected to (a) physical violence, (b) psychological violence and (c) sexual violence in the previous 12 months. The potential contribution of some of the identified citizen science initiatives, e.g., SafeCity, HarrasMap, etc., to this indicator was unclear to the chief statistician of the UN Environment due to her limited knowledge on the methodology of this indicator. Hence, the lead author consulted the Head of the Research and Trend Analysis Branch of the UNODC, the custodian agency responsible for many of the SDG 16 indicators, who confirmed the potential complementarity of such initiatives to inform this indicator, which was then used in the final mapping. Evidence of these contacts is provided in Table S1. After this second peer review process, the final mapping of citizen science to the SDG indicators was completed in step 7. The final mapping results are provided as Table S1 in the Supplementary Material.

\section{Compilation of results}

Once the entire SDG indicator mapping exercise was completed, the results in Table S1 were summarized according to the categories of "already contributing", "could contribute" and "no alignment at present" to understand the current situation by SDG, tier classification, and custodian agency. The results were also compared to the mapping exercise undertaken by GEO to see where there are overlaps between contributions that could be jointly made from citizen science and EO. Finally, we provide examples by indicator to demonstrate where citizen science is already contributing and where it has the potential to contribute in the future.

\section{Results}

The results of the SDG indicator review process are summarized in Figs. 2, 3, and 4. The full review by indicator can be found in Table S1 of the Supplementary Material. All SDGs have at least one indicator to which citizen science could potentially contribute (Fig. 2). Moreover, citizen science is already contributing to the monitoring of 5 SDG indicators, and could contribute, by providing direct or supplementary information, to 76 indicators. For the remaining 165 indicators, we could not identify any ongoing or past citizen science initiatives. Thus, this analysis reveals that citizen science data are already contributing or could contribute to the monitoring of around 33\% of the SDG indicators. Note that the total in this analysis is 246 indicators rather than 244 indicators because 2 indicators are counted twice (9.1.1 Proportion of the rural population who live within $2 \mathrm{~km}$ of an all-season road and 14.1.1 Index of coastal eutrophication and floating plastic debris density). These two indicators contain examples of citizen science initiatives that are already contributing, as well as those that could contribute. For example, Litter Intelligence is a citizen science initiative producing data that already contribute to the reporting of indicator 14.1.1 on marine litter by Stats New Zealand, and projects such as the Australian Marine Debris Initiative, Open Litter Map, and Marine Debris Tracker have great potential to contribute data to 14.1.1 in the future.

Our assessment highlights that the greatest contributions of citizen science (current and potential future contributions combined) to the SDG indicator framework would be in SDG 15 Life on Land (64\%); SDG 11 Sustainable Cities and Communities (60\%); SDG 3 Good Health and Wellbeing (56\%); and SDG 6 Clean Water and Sanitation (55\%). This is illustrated in Fig. 2, showing pie charts of the current and potential citizen science contributions to SDG monitoring by goal. This also demonstrates that citizen science data have the greatest potential for input to the environmental SDG indicators. Of the 93 environmental indicators in the SDG indicator framework (UN Environment 2019), citizen science could provide inputs for 37 (around 40\%) indicators.

Additionally, our analysis identified overlap between contributions from citizen science and EO based on the mapping exercise undertaken by GEO (2017) (Fig. 2). Of the 29 indicators identified by GEO (2017), our assessment shows that citizen science could support 24 out of the 29 indicators, which cover 11 of the SDGs. Hence there is potential for citizen science and $\mathrm{EO}$ approaches to complement each other.

Results indicate that citizen science could help to monitor 33 Tier I indicators (out of 110), 41 Tier II indicators (out of 104), and 7 Tier III indicators (out of 40) based on the Tier Classification for SDG Indicators as of 13 April 2019, 


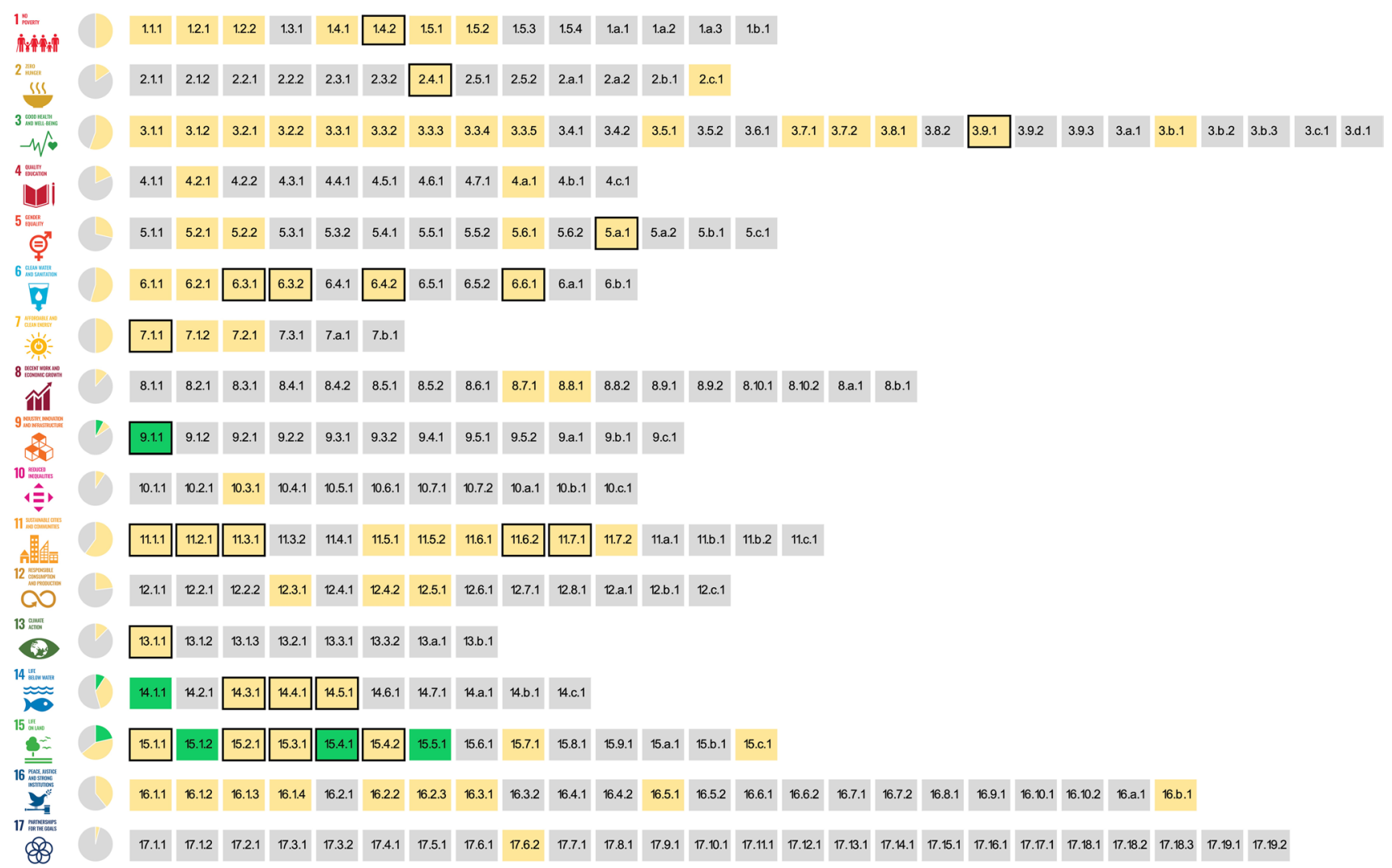

Fig. 2 The SDG indicators where citizen science projects are "already contributing" (in green), "could contribute" (in yellow) or where there is "no alignment" (in grey). The overall citizen science contributions to each SDG are summarized as pie charts. Black borders around indicators show the overlap between citizen science and EO, as identified by GEO (2017)

Fig. 3 Citizen science contributions to SDG monitoring by tier classification. The green shading denotes direct contributions, the yellow are supplementary contributions, and the orange shows indicators that have both direct and supplementary contributions. The values within each box are the SDG indicator numbers.

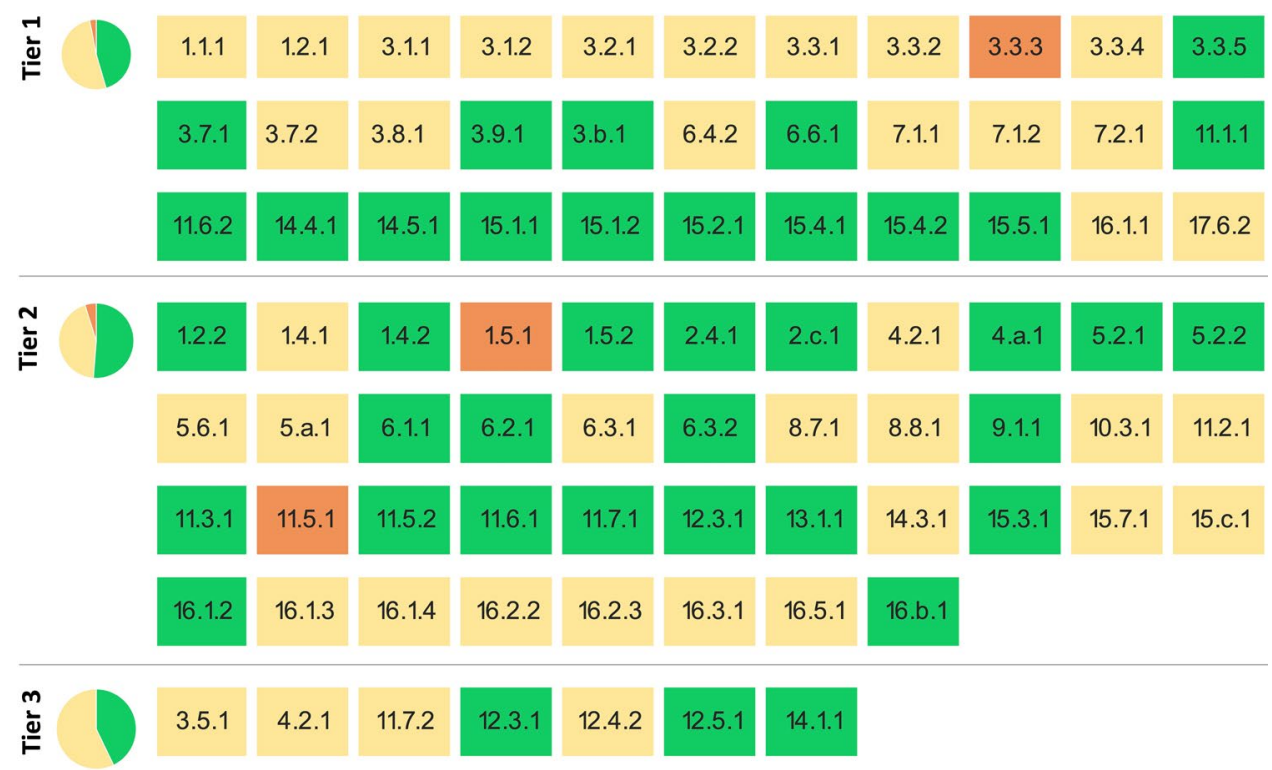

when the data were downloaded (Fig. 3). The total number is 254 instead of 244 as some indicators are allocated to more than one tier. This equates to $30 \%$ for Tier I, $40 \%$ for
Tier II and $18 \%$ for Tier III indicators. These results suggest that citizen science has the greatest potential to contribute to Tier II indicators, when the current and past initiatives are 


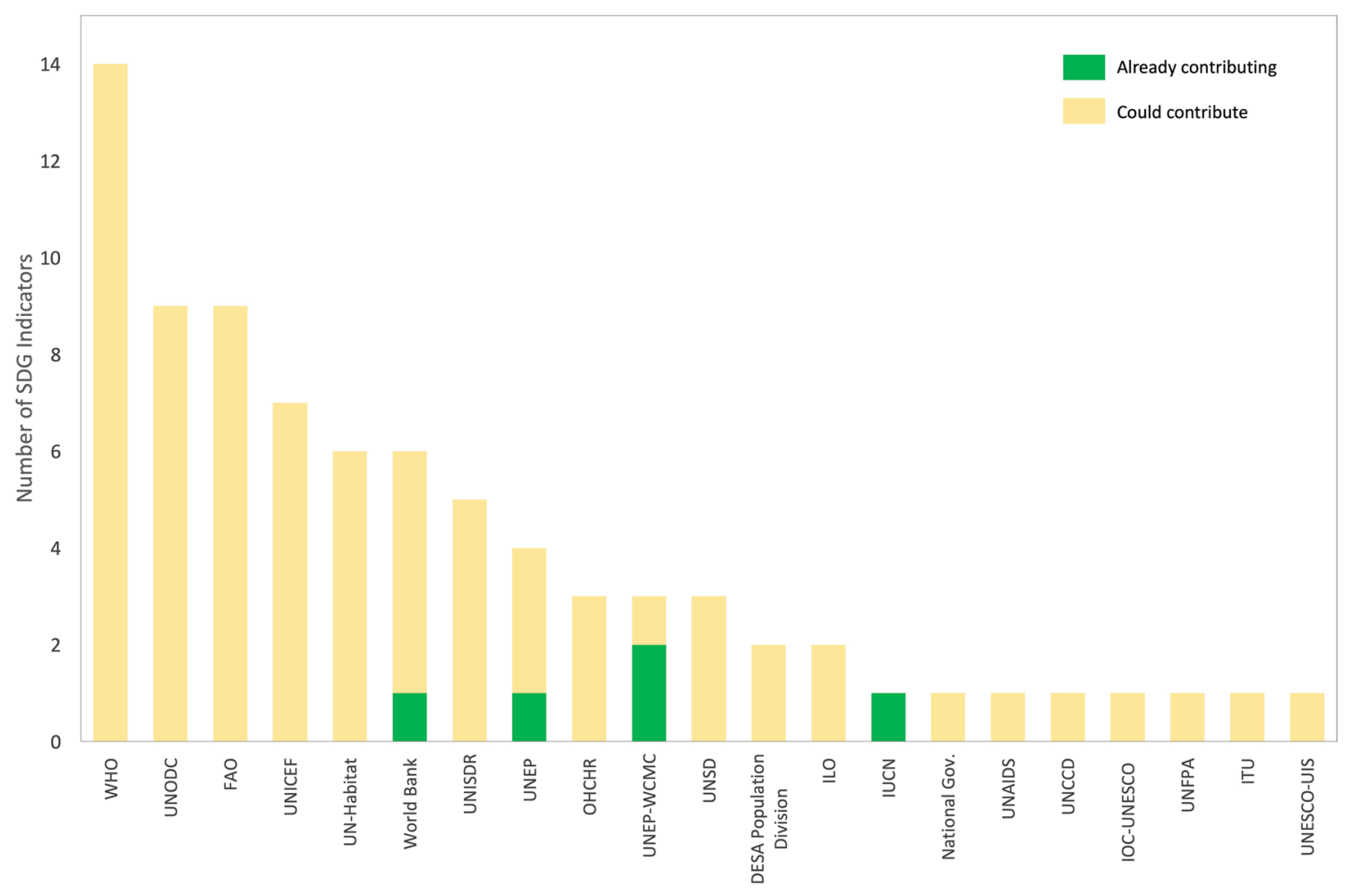

Fig. 4 The number of SDG indicators by custodian agency to which citizen science could contribute

considered. Methodologies for how to collect data already exist for Tier II indicators. However, countries do not produce the data regularly due to poor statistical capacity, lack of resources, political reasons, and other factors. Citizen science could inform such indicators to fill the identified data gaps (see indicator 6.3.2 below). As for the Tier I indicators, even though agreed methods exist and the data are widely available, not all countries are at the same level in the production of data needed to track their progress. For example, as of the year 2016, data for the Tier I indicator on extreme poverty (indicator 1.1.1) have been lacking for 72 countries for over 15 years (Dunning and Kalow 2016). In addition, there are opportunities to use citizen science for improving the temporal frequency and spatial resolution of Tier I and II indicators (Dickinson et al. 2010), which could complement the national reporting. Finally, citizen science data have the potential to contribute to Tier III indicators, as they have no established methodology and standards to support them. Citizen science could be introduced as part of the methodology development process for relevant Tier III indicators by the responsible custodian agencies, e.g., as implemented for indicator 14.1.1 on marine plastics by UN Environment (see indicator 14.1.1 below).

Figure 3 also highlights the indicators where citizen science makes direct contributions, supplementary contributions, or where an indicator has both a direct and supplementary contribution from citizen science. Of the 81 indicators shown in Fig. 3, $39(\sim 48 \%)$ make or can make a direct contribution, $39(\sim 48 \%)$ can make a supplementary contribution and $3(\sim 4 \%)$ can make both. Thus, citizen science has nearly equal value in terms of direct and supplementary contributions to the SDGs.

Figure 4 shows the custodian agencies that could benefit from the citizen science data, since each indicator has at least one custodian agency responsible for that indicator. The custodian agencies that have the greatest potential in terms of benefiting from citizen science data are WHO, UNODC, FAO, the UN Children's Fund (UNICEF), UN-Habitat, the World Bank, the UN Office for Disaster Risk Reduction (UNISDR) and UN Environment. The citizen science community could focus on creating partnerships with these agencies around the specific indicators illustrated in Fig. 2.

Having presented the overall picture, we now provide specific examples of our results that demonstrate where citizen science is already contributing to the SDGs and where it has the potential to contribute in the future.

\section{Indicators where citizen science is "already contributing" to SDG monitoring}

As there are only five indicators where citizen science is already contributing to SDG monitoring, all five are described in more detail below. 


\section{Indicator 9.1.1 Proportion of the rural population who live within $2 \mathrm{~km}$ of an all-season road}

SDG indicator 9.1.1, also known as the Rural Access Index (RAI), measures the share of a country's rural population that lives within $2 \mathrm{~km}$ of an all-season road (defined as a road that is motorable in all weather conditions), which is important for access to markets and economic activities, as well as social and administrative services (UN 2019d). The World Bank, custodian agency for 9.1.1, typically receives data from national road agencies and national statistical offices (NSOs) directly, and reviews their results to be included in the global SDG data set. In 2018, data were available for 20 countries and consultations are ongoing for more (UN 2019d).

OpenStreetMap is an online crowdsourced communitydriven project to create an open, editable, and free map of the world (Mooney and Minghini 2017). These maps are used in a variety of ways, from basic navigation purposes to disaster response and humanitarian aid (Minghini et al. 2017). Metadata for indicator 9.1.1 refers to OpenStreetMap as an alternative source of data for countries that do not have sufficient road location information available or it is completely missing (UN 2019d). In addition, measuring the RAI using OpenStreetMap in $120+$ countries is a work in progress at the World Bank (Vincent 2018). Hence, citizen science is already contributing to this indicator.

\section{Indicator 14.1.1 Index of coastal eutrophication and floating plastic debris density}

SDG indicator 14.1.1 is a Tier III indicator that has no established methodology. It is quite broad in scope, and the work plan includes four types of sub-indicators for coastal eutrophication and another four for marine litter focusing on plastics. Plastic waste is a serious threat to the environment and human health. However, the amount of plastics entering the ocean from land-based sources is currently unknown. An estimate indicates that 5-13 million tons of plastics generated on land entered the marine environment in 2010 alone (Jambeck et al. 2015). UN Environment, the custodian agency for this indicator, is currently developing a methodology that uses citizen science data as a primary source of information for measuring marine plastics on beaches and shorelines. The methodology is currently being tested in two pilot countries, Kenya and Mauritius, which will be extended to seven additional countries in Asia and Africa in 2020. The methodology development process will be finalized by October 2019, which will then be scaled up to more countries around the globe from 2020 onwards (Campbell et al. 2019).

In addition to the methodology development efforts for 14.1.1 at the global level, there are also activities taking place at a national level in New Zealand. Litter Intelligence is a large-scale citizen science program led by the charity group Sustainable Coastlines. Sustainable Coastlines has been collaborating with the Ministry for the Environment, Stats New Zealand and the Department of Conservation since the design phase of the program in 2016 to ensure that the data produced by citizens are of an appropriate standard and of high enough quality for use in environmental reporting by government bodies nationwide, including the SDGs. The result is that the initial Litter Intelligence data set will be included in the official environmental report 'Marine 2019' produced by the Ministry for the Environment and Stats New Zealand (Howitt 2019).

\section{Indicators 15.1.2 Proportion of important sites for terrestrial and freshwater biodiversity that are covered by protected areas, by ecosystem type and 15.4.1 Coverage by protected areas of important sites for mountain biodiversity}

Citizen science is currently informing SDG indicators 15.1.2 and 15.4.1 on biodiversity and protected areas through the Important Bird and Biodiversity Area (IBA) and Key Biodiversity Area (KBA) schemes (SDSN TReNDS 2019; Fritz et al. 2019). Of the existing KBAs, which are sites designated as significantly contributing to global biodiversity, $44 \%$ of freshwater and $47 \%$ of terrestrial KBAs are covered by existing protected area boundaries (UNEP-WCMC et al. 2018). The largest subset of KBAs is identified using data on birds including IBAs (UN 2019d) .

Most citizen science globally engages members of the public to contribute observations of nature or annotate data from nature online (Chandler et al. 2017). Observations of birdwatchers, in particular, has dramatically increased collective knowledge of many bird species, as exemplified by many peer-reviewed academic publications that include observation data from around the world (https://ebird.org/ science/publications). The platform eBird alone acquires around 7.5 million bird observations on a monthly basis and more than 100 million bird sightings per year (https://ebird .org/). In addition to eBird, initiatives around the world such as Bird Track, Seabirds, the PanEuropean Common Bird Monitoring Scheme, along with other resources that include published and unpublished literature and expert reviews, provide data that are used for the identification of IBAs and KBAs (Butchart 2019).

Although indicator 14.5.1 Coverage of protected areas in relation to marine areas is also related to protected areas, in contrast to 15.1.2 and 15.4.1, the current methodology does not include the KBA scheme. Therefore, the aforementioned projects are listed as "could be used" and not "already contributing" to this indicator (Campbell 2019). 


\section{Indicator 15.5.1 Red List Index}

The Red List Index is compiled by the International Union for Conservation of Nature and Natural Resources (IUCN) and is also referred to as the IUCN Red List of Threatened Species. The Red List Index captures risk of extinction over time for birds, mammals, amphibians, and corals. BirdLife International, which has a network of volunteer observers collecting data on bird populations, is the official contributor of information on threatened bird species to the Red List Index. BirdLife International also uses data from citizen science projects such as eBird to compile the list. Hence citizen science is already contributing to indicator 15.5.1.

\section{Examples of SDG indicators where citizen science 'could contribute' to SDG monitoring}

As there are several examples of where citizen science 'could contribute' to SDG monitoring, only some examples are described below. See Table S1 in the Supplementary Materials for additional examples.

\section{Indicator 1.5.2 Direct economic loss attributed to disasters in relation to global gross domestic product (GDP)}

SDG indicator 1.5.2 is about quantifying direct economic losses that result from a disaster. The metadata for this indicator defines the direct economic loss as the "monetary value of total or partial destruction of physical assets existing in the affected area-direct economic loss is nearly equivalent to physical damage" (UN 2019d). There are a number of different citizen science initiatives that could help in quantifying damage. For example, Picture Pile is a project where volunteers classify satellite images to identify damaged buildings after a disaster for post disaster damage assessment (Danylo et al. 2018). In Humanitarian OpenStreetMap, participants digitize the areas affected by disasters, which includes identifying damaged roads for disaster responders to reach those in need (HOTOSM 2016). MicroMappers is another initiative that combines crowdsourcing of damaged buildings using drone imagery and artificial intelligence to train algorithms to sort through crowdsourced data for the purposes of disaster response (Givoni 2016). As the identification of damaged assets is needed to measure the direct economic loss, these, and other similar projects, could be used for monitoring progress on this indicator.

\section{Indicator 3.3.3 Malaria incidence per 1000 population}

We have identified several citizen science initiatives that could provide direct or supplementary information for the monitoring of indicator 3.3.3. For example, MAHEFA (MA-lagasy HE-althy FA-milies) was a community-based health project run by USAID and the Madagascan Ministry of Public Health from 2011 to 2016. As part of the program, thousands of community health volunteers were chosen by their own communities to be trained in providing basic health care services and identifying serious cases. In Analalava, community health volunteers provided a wide range of services including promoting good health practices and hygiene, offering family planning services, diagnosing and treating simple cases of malaria, diarrhea and pneumonia for children under age 5 , and raising childhood immunization (USAID 2015). MAHEFA Miaraka is the continuation of the MAHEFA program, running between 2017 and 2021 (USAID 2017). Although primarily designed for action rather than monitoring purposes, initiatives such as MAHEFA could inform this indicator.

In addition, some citizen science projects are aimed at measuring mosquito populations at the national and global levels through different types of activities and data collection protocols. These include Mosquito Alert (Palmer et al. 2018), a project that monitors adult species presence, and the GLOBE Mosquito Habitat Mapper, which monitors breeding grounds (https://www.globe.gov/web/globe -mosquito-project). The Global Mosquito Alert Consortium (Tyson et al. 2018) is a consortium of citizen science mosquito monitoring projects that collaborate on protocols and data sharing. Global Mosquito Alert could also support this indicator by providing supplementary information on mosquito populations and their possible breeding sites, in a coordinated way, that allows for local differences in monitoring methodologies (such as focusing on adults or breeding grounds), but also supports coordination and data sharing.

\section{Indicator 6.3.2 Proportion of bodies of water with good ambient water quality}

This indicator aims to measure the proportion of water bodies in a country with good water quality. Although an established methodology exists for 6.3.2, the data are not regularly produced (Tier II) as substantial investments in financial and human resources are required for organizing routine data collection activities at high spatial and temporal resolutions. Accordingly, many of the least developed countries do not collect data on water quality or they have very limited monitoring programs available (UN 2019d). To address these data gaps and supplement the existing authoritative data, the metadata of 6.3.2 refer to citizen science as an additional source of information (Quinlivan et al. 2019).

Citizen science initiatives such as FreshWaterWatch could provide meaningful contributions to the monitoring 
of this indicator. FreshWaterWatch has a global water quality database based on the contributions made by $8,000+$ citizen scientists for more than 2,500 water bodies (freshwaterwatch.thewaterhub.org, 2019). Other projects, including Secchi Dip-In (Bigham Stephens et al. 2015), Lake Observer (Carey et al. 2019), Citclops (Busch et al. 2016), Opal Water Survey (Rose et al. 2016) and many more, could also inform this indicator. Given the potential of citizen science to support 6.3.2 and the large data gaps that exist, the custodian agency, UN Environment, can play a more active role by encouraging countries to apply citizen science to monitor water quality, and by providing guidelines for initiating and implementing citizen science projects at a local or national level.

\section{Indicator 11.6.2 Annual mean levels of fine particulate matter (e.g., PM2.5 and PM10) in cities (population weighted)}

This Tier I indicator is modeled by the World Health Organization (WHO) using recorded measurements of particulate matter that is approximately 2.5 and 10 microm or less in diameter (abbreviated as $\mathrm{PM}_{2.5}$ and $\mathrm{PM}_{10}$, respectively) from official pollution monitoring stations around the world, incorporating around 3000 station inputs. Global and regional estimates are weighted by national populations. In addition to these official monitoring stations, there are several citizen science projects, both past and current, that involve citizens in measuring $\mathrm{PM}_{2.5}$ and $\mathrm{PM}_{10}$. For example, the EU-funded CitiSense project, which ended in 2016, experimented with many low-cost pollution monitoring sensors over the lifetime of the project, during a time when low cost sensor technology was evolving rapidly. The HackAir project, which also recently ended, still provides advice on its website for building Do-It-Yourself low cost pollution sensors that measure $\mathrm{PM}_{2.5}$ and for then linking these measurements to an online map. Two ongoing citizen science projects, AirCasting and AirVisual, have developed sensors that measure $\mathrm{PM}_{2.5}$ but cost in the order of 250 USD. Hence there are increasingly larger numbers of sensors being deployed by citizens that could contribute measurements to WHO's model. However, data quality remains an issue due to the need to calibrate the sensors and variations in sensor performance caused by temperature and humidity (Liu et al. 2019). Nevertheless, citizen science is valuable for detecting changes in previous levels of $\mathrm{PM}_{2.5}$ and $\mathrm{PM}_{10}$ and to provide detailed spatial distributions across cities, which cannot be produced with the current density of official stations.
Indicator 15.1.1 Forest area as a proportion of total land area

This Tier I indicator reports forest area as a proportion of total land area in a country (UN 2019d). This is currently measured through FAO's Forest Resources Assessment exercise, undertaken every 5 years. However, citizen science initiatives such as Global Forest Watch, Picture Pile, FotoQuest Go and other similar projects could inform this indicator by improving individual country estimates or providing more frequent updates. Global Forest Watch is an online forest monitoring platform, where volunteers around the world can monitor and report on global forests in near real time; it combines different sources of data including satellite technology and citizen science to enable access to timely and reliable data on forests. Picture Pile has been used in the past to map deforestation by asking volunteers to sort millions of pairs of satellite images to identify evidence of deforestation. Future campaigns could contribute to better mapping of deforestation and forest areas, and complement current national forest inventories or remote sensing approaches.

\section{Examples of indicators with 'no alignment at present'}

In our analysis, we identified 165 indicators that have no alignment with any ongoing or past citizen science initiatives. These are mostly policy-relevant indicators that are designed to monitor a policy or a national or global initiative and depend on official records and statistics, such as 6.5.1 Degree of integrated water resources management implementation or 12.7.1 Number of countries implementing sustainable public procurement policies and action plans. For example, the indicator 6.5.1 on the degree of implementation of integrated water resources management is based on a national survey structured around (i) an enabling environment that includes policies, laws, plans; (ii) institutions such as political, social, economic institutions; (iii) management instruments that are tools and activities that enable informed decisions; and finally (iv) financing made available to achieve integrated water resources management. Answers to the survey need to be provided by countries following a stakeholder consultation. This is an indicator that is not amenable to citizen science approaches as the data collection is purely policyrelevant and therefore the responsibility of governments as described in the indicator methodology. 12.7.1 is another example of an indicator that will rely on the results of a global review survey. The survey will be filled out by the countries as stated in the work plan of the indicator, as no established methodology currently exists for the indicator 
(Tier III). Other examples of policy-relevant indicators that are not amenable to citizen science approaches include 8.b.1 Existence of a developed and operationalized national strategy for youth employment, as a distinct strategy or as part of a national employment strategy or 1.5.4 Proportion of local governments that adopt and implement local disaster risk reduction strategies in line with national disaster risk reduction strategies.

Indicators with financial focus constitute another group that typically does not align with citizen science approaches. Examples of this group include the indicator 1.a.2 Proportion of total government spending on essential services (education, health and social protection) or 4.b.1 Volume of official development assistance flows for scholarships by sector and type of study or 17.17.1 Amount of United States dollars committed to (a) public-private partnerships and (b) civil society partnerships.

\section{Discussion}

Our research is the first comprehensive analysis on the contribution of citizen science to SDG monitoring at the indicator level. Previous work has only considered the potential of citizen science at the levels of goals and targets (West and Pateman 2017; Bio Innovation Service 2018) or provided only a few examples of where citizen science data are already contributing to some of the SDG indicators (Fritz et al. 2019). Other similar analyses include reports looking at the contribution of citizen-generated data to the SDGs focusing on a few case studies (Gray et al. 2016; Datashift 2017; Lämmerhirt et al. 2018). However, their mapping did not include the complete set of 244 SDG indicators.

The most remarkable finding from this review process is that citizen science has the potential to contribute to all 17 SDGs, since it is already contributing or could contribute to at least one indicator per goal. The contributions were evenly split between direct and supplementary (each $\sim 48 \%$ ), indicating that citizen science can benefit the SDG indicator framework in different ways. This includes, but is not limited to, citizen science being the primary source of data that is used to measure progress on the indicator or filling spatial or temporal gaps in our knowledge. For example, household surveys, as the main data source for one third of all SDG indicators (ISWGHS 2019), can benefit from citizen science approaches. Citizen science could complement household surveys at a local level by providing more granular data to inform local decision making processes through involving community members to collect data. The Uganda Bureau of Statictics has already used this approach as part of its Community Information System program (Lämmerhirt et al. 2018). Uwezo, a project started in 2009 in Kenya to evaluate the levels of literacy and numeracy, conducted large scale household assessments led by citizens in Kenya, Tanzania and Uganda. Although the survey design and sampling processes would require more collaboration with official institutions, Uwezo's results served the purpose of highlighting issues around education in a well-documented way with officially recognized evidence. Uwezo's work has contributed to a shift in the way that literacy should be officially measured. Several ministries of education have used, acknowledged or drawn upon Uwezo's results (Gray et al. 2016). This example also highlights the potential of using citizen science to assess the processes and results of household surveys, which in a way constitutes a "monitoring of the monitoring process". Understanding the metadata for indicators, existing data sources to measure indicators and national practices, as well as the data gaps and potential will be an important step forward in ensuring appropriate use of citizen science data.

The greatest contributions of citizen science are in the environmental domain, such as indicators found in SDG 15 Life on Land; SDG 11 Sustainable Cities and Communities; and SDG 6 Clean Water and Sanitation. This makes sense, given that citizen science is highly focused on environmental monitoring (Kullenberg and Kasperowski 2016). Yet, we also uncovered strong potential for citizen science in SDG 3 Good Health and Wellbeing. Tier I and II indicators are where citizen science could make the most significant contributions in terms of the number of indicators (75 in total) compared to only 8 in Tier III. Although these indicators may already be established in terms of either methodology and/or data collection, citizen science can, nevertheless, provide inputs at a national level, particularly in terms of higher temporal and spatial frequencies. Although Tier III indicators were thought to have the greatest potential regarding citizen science (Fritz et al. 2019), only through such a comprehensive mapping can we see that this potential is smaller than originally anticipated. However, even for these eight indicators, there is still scope to work with custodian agencies and NSOs to explore the potential of citizen science, in particular, to use citizen science to help in devising the methodology.

Even though difficult to generalize and define in concrete terms due to the unique methodologies of each indicator, including the suggested sources of data for measuring them and proposed compilers of these data, our analysis shows that some indicators could be more amenable to citizen science than others. In addition to the environmental indicators mentioned above, these include indicators that could benefit from observations such as bird and biodiversity monitoring (15.1.2, 15.4.1) or monitoring of land use and land cover changes $(15.1 .1,15.2 .1)$. Other indicators that align well with citizen science approaches would be ones that could be supported by spatial data. For example, monitoring of water 
quality (6.3.2) or air quality (3.9.1), disease threats (3.3.3), post disaster damage assessment (1.5.2) or open spaces in cities (11.7.1). Another group would be indicators that could be supplemented through self-reporting such as sexual violence (16.1.3) or perception of safety (16.1.4). More generically, it appears likely that indicators measuring issues that raise a concern among citizens and communities are more amenable to citizen science. The reason for this may be these issues affect or could affect their health, environment and quality of life.

We also examined the overlap between contributions from citizen science and EO to the SDG indicators, which was the case for 24 indicators, to identify the potential for these 2 data sources to complement each other. For example, citizen science can support EO in two different ways: satellite (and other remotely sensed) image interpretation and data collection, which could help in the calibration and validation of products generated by remote sensing (See et al. 2016). The GEO Global Agricultural Monitoring (GEOGLAM) is an initiative that aims to strengthen global agricultural monitoring by improving the use of remote sensing tools for crop production projections and weather forecasting. GEOGLAM could support some SDG targets under SDG 1 and SDG 2, including target 2.c Adopt measures to ensure the proper functioning of food commodity markets and their derivatives and facilitate timely access to market information, including on food reserves, to help limit extreme food price volatility. GEOGLAM relies on satellite EO data and in-situ measurements, as well as other citizen science platforms using crowdsourced approaches such as Geo-Wiki (GEO 2017).

The SDG indicator framework is a work in progress. The tier classification for indicators is regularly reviewed and updated as new methodologies are designed for Tier III indicators or more data become available to measure them. In addition, the 51 st session of the UN Statistical Commission (UNSC) in 2020 will be the first comprehensive review of the SDG indicators. The review is expected to cover 37 new indicators for 14 goals (Adams 2019). Therefore, this assessment will need regular updating as the SDG indicator process progresses over time.

During our mapping, we additionally identified indicators for which citizen science data could be used as a source of information if there were relevant projects in the future. However, these were not included in the current mapping. For example, we could not identify any past or ongoing citizen science project that could support indicator 2.1.1 Prevalence of undernourishment, yet citizen science could be used as an approach for understanding diets and developing interventions in the future. Hence, further research could be done on the potential of citizen science more generally for the SDGs.
Finally, we do acknowledge that not all projects might be included in our mapping due to the broad scope of citizen science as a concept, with many different terms used to define these activities (Eitzel et al. 2017), as well as the vast range and number of citizen science initiatives worldwide. Language was another issue; most of the initiatives we mapped were in English. Therefore, a local scale, citizen science project in another language may not be covered. However, creating an exhaustive list of all citizen science initiatives worldwide was not the aim of this paper. Instead, our goal was to identify at least one project in which the data are supporting, or could support, the SDG monitoring process. Hence, we propose that this work could serve as the basis for more elaborate research focusing on one or more specific goals or targets, studying the methodologies and approaches used by identified citizen science initiatives and providing guidelines on including them in official statistics.

\section{Conclusions and next steps}

In this study, we undertook a systematic review of the 244 SDG indicators, characterizing each one by whether citizen science is already contributing, could contribute or has no alignment at present.

In our analysis, we identified the barriers to the implementation of the SDGs from the perspective of data gaps and needs. Even though data availability has improved significantly in the last decade, there are still major gaps in the supply of reliable, timely and actionable information that could be used to inform policies. Most countries do not regularly collect data for more than half of the global indicators (UN 2019a). Countries in Africa and Asia, on average, have data available to monitor only about $20 \%$ of SDG indicators (UN 2018; SDSN TReNDS 2019). Moreover, $68 \%$ of the environmental SDG indicators lack data (UN Environment 2019). Encouragingly, our results show that citizen science is already contributing or could contribute data to $40 \%$ of the environmental SDG indicators. However, this untapped potential of citizen science for tracking SDG progress is yet to be realized as many of the citizen science initiatives we identified as part of this study as having great potential to contribute to SDG monitoring are currently not feeding into this process. They require different levels of modification and improvement to be used for SDG monitoring and reporting purposes including standardization and use of quality assurance processes. Improving the quality of the data is clearly a need, but assessing and quanitfying the quality of data is still an area of debate. Askham et al. (2013) define data quality according to six core dimensions, and citizen science may have particular impact on two of those dimensions for improving the monitoring of SDGs: 
Completeness, filling all the identified data gaps for SDG monitoring (UN Environment 2019) and Timeliness providing early warning of hazards, and reducing the disaster risk (Hicks et al. 2019), with the consequent improvement of several SDGs (Kelman 2017).

Realizing the full potential of citizen science data depends on creating an enabling environment. This could be done through, for example:

(i) building awareness and sharing experiences on the use of citizen science for the SDGs, which could be achieved by integrating the citizen science community into the SDG monitoring processes through initiatives such as the Community of Practice on the SDGs and Citizen Science (SDGs CoP) established as part of the EU-funded WeObserve project;

(ii) developing case studies or success stories where citizen science data have been used in innovative ways by NSOs and disseminating these using channels such as the SDGs CoP, data and statistics events and conferences, etc. that will reach governments, NSOs, custodian agencies and other SDG stakeholders;

(iii) identifying criteria for ensuring data quality or data quality assurance procedures, drawing upon a vast literature that already contains many different types of quality assurance processes and based on citizen science project experiences of successful techniques. This should be coupled with requirements from NSOs and other government agencies regarding their quality standards and protocols.

(iv) integrating citizen science into the methodologies of SDG indicators, learning lessons from the current example of integrating citizen science as the source of data into the methodology of indicator 14.1.1 on marine debris;

(v) promoting consistent data collection across citizen science initiatives through aligning definitions with global definitions that would allow internationally comparable methodologies and harmonized data collection and sharing, which can be achieved through working groups (WGs) initiated by the citizen science community or new WGs that could be led by relevant UN agencies;

(vi) supporting open citizen science data that are formatted using standards, e.g., a new data and metadata standard for Public Participation in Scientific Research (PPSR) is currently being developed by citizen science associations in the United States, Europe and Australia in partnership with SciStater. com; and

(vii) sustaining citizen science initiatives through innovative funding schemes, e.g., European funding initiatives such as the 'Science with and for Society' pro- gramme, national research funding schemes, green business funding, crowdfunding platforms, etc.

Partnerships between governments, NSOs, and citizen science practitioners are key to turning these ideas into achievable actions that could also lead to building on each other's experiences, needs, and capacities. For example, the SDGs CoP is an initiative established to foster collaboration and consolidate knowledge and experience on citizen science and the SDGs across stakeholders.

Although data from citizen science may be considered a low-cost option, the data are not free nor are they necessarily interoperable with systems employed by NSOs. We need further developments in citizen science data collection and analytical tools, data validation processes, interoperability, etc., to ensure that the data are structured in a way that is of high quality, comparable, and could inform policy. This requires investment and hence clear business cases. Many of these challenges are echoed in the need for a digital ecosystem for the planet (Campbell and Jensen 2019), where citizen science is one of the data sources identified for powering this network. In addition, the potential of citizen science as a data source for monitoring the SDGs-especially for improving the temporal scale-also relies on the sustainability of the citizen science initiatives. Moreover, the enabling environment for citizen science requires innovative funding schemes, as well as careful attention to the incentives and barriers for continued participation by citizen scientists (Wehn and Almomani 2019).With the current challenges of climate change and environmental degradation, the future of the planet depends on better data to stimulate meaningful action and decisions (IAEG Secretariat 2014; Jensen and Campbell 2019). As a rapidly growing and transforming field, citizen science has considerable potential to interact with the fast evolving SDG process, not just as a source of data that could fill gaps or improve rapid response to disasters, but as a science-driven approach that places citizens at the heart of SDG monitoring. Citizen science provides the public with the means to inform policy, which could raise trust, credibility and ultimately accountability in the SDG monitoring process. Moreover, engaging with citizens in the data collection process, and in research more generally, could create opportunities to stimulate citizen action. Implementation of the SDGs requires changes to existing decision making procedures and practices across governance structures, economic sectors and society at large. Citizen science not only 'delivers' more complete and timely data but can also trigger shifts in governance structures and accountability, which imply changes for public authorities in terms of both the basis for their decisions (what evidence and how this is taken into account) as well as in their interactions with the public in terms of continuity and responsiveness (Wehn et al. 2015). 
Acknowledgements Open access funding provided by International Institute for Applied Systems Analysis (IIASA). We would like to acknowledge the inputs from Muki Haklay (UCL), Camden Howitt (Litter Intelligence), Stuart Butchart (Birdlife), Kyle Copas (GBIF), Stephanie Burrows (WHO), Angela Me (UNODC), Sven Schade (JRC), Maria Paola Rizzo (FAO), Umar Serajuddin and Atsushi Iimi (World Bank) and Esther Motjer i Ayats (Science for Change) in discussions about citizen science contributions to specific SDG indicators. We would also like to acknowledge ongoing intellectual support from SDSN TReNDS. This research received funding from the EU FP7 ERC CrowdLand project (No. 617754) and the EU Horizon 2020 research and innovation programme under the WeObserve project (No. 776740).

Open Access This article is licensed under a Creative Commons Attribution 4.0 International License, which permits use, sharing, adaptation, distribution and reproduction in any medium or format, as long as you give appropriate credit to the original author(s) and the source, provide a link to the Creative Commons licence, and indicate if changes were made. The images or other third party material in this article are included in the article's Creative Commons licence, unless indicated otherwise in a credit line to the material. If material is not included in the article's Creative Commons licence and your intended use is not permitted by statutory regulation or exceeds the permitted use, you will need to obtain permission directly from the copyright holder. To view a copy of this licence, visit http://creativecommons.org/licenses/by/4.0/.

\section{References}

Adams B (2019) Commentary on special issue: knowledge and politics in setting and measuring SDGS numbers and norms. Global Policy 10:157-158. https://doi.org/10.1111/1758-5899.12639

Asaba E, Suarez-Balcazar Y (2018) Participatory research: a promising approach to promote meaningful engagement. Scandinavian J Occupat Therapy 25:309-312. https://doi.org/10.1080/11038 128.2018.1541224

Askham N, Cook D, Doyle M, et al (2013) the six primary dimensions for data quality asessment: defining data quality dimensions. Available at: https://www.whitepapers.em360tech.com/wp-conte nt/files_mf/1407250286DAMAUKDQDimensionsWhitePaperR3 7.pdf

Bigham Stephens DL, Carlson RE, Horsburgh CA et al (2015) Regional distribution of Secchi disk transparency in waters of the United States. Lake Reservoir Manage 31:55-63. https://doi. org/10.1080/10402381.2014.1001539

Bio Innovation Service (2018) Citizen Science for Environmental Policy: development of an EU-wide inventory and analysis of selected practices. Final report for the European Commission, DG Environment under the contract 070203/2017/768879/ETU/ ENV.A.3, in collaboration with Fundacion Ibercivis and The National History Musuem

Busch J, Bardaji R, Ceccaroni L et al (2016) Citizen bio-optical observations from coast- and ocean and their compatibility with ocean colour satellite measurements. Remote Sensing 8:879. https://doi. org/10.3390/rs8110879

Butchart S (2019) Personal communication, BirdLife International

Campbell J (2019) Personal communication, UN Environment

Campbell J, Bowser A, Fraisl D, Meloche M (2019) Citizen Science and Data Integration for Understanding Marine Litter. In: Data for Good Exchange, 15 Sept 2019 Available at: https://pure.iiasa .ac.at/id/eprint/16095/

Campbell J, Jensen D (2019) The promise and peril of a digital ecosystem for the planet. Available at: https://medium.com/@david edjensen_99356/building-a-digital-ecosystem-for-the-plane $\mathrm{t}-557 \mathrm{c} 41225 \mathrm{dc} 2$

Carey CC, Ward NK, Farrell KJ et al (2019) Enhancing collaboration between ecologists and computer scientists: lessons learned and recommendations forward. Ecosphere 10:e02753. https://doi. org/10.1002/ecs 2.2753

CEOS (2018) Satellite earth observations in support of the sustainable development goals. special 2018 edition. Available at: https ://eohandbook.com/sdg/files/CEOS_EOHB_2018_SDG.pdf

CEOS (2015) Applications of satellite earth observations: serving society, science and industry. Available at: https://ceos.org/docum ent_management/Publications/Data_Applications_Report/DAR_ Summary-Brochure_Digital-Version_Dec2015.pdf

Chandler M, See L, Copas K et al (2017) Contribution of citizen science towards international biodiversity monitoring. Biol Cons 213:280-294. https://doi.org/10.1016/j.biocon.2016.09.004

Conrad CC, Hilchey KG (2011) A review of citizen science and community-based environmental monitoring: issues and opportunities. Environ Monit Assess 176:273-291. https://doi.org/10.1007/ s10661-010-1582-5

Coulson S, Woods M, Scott M, Hemment D (2018) Making Sense: empowering participatory sensing with transformation design. Design Journal 21:813-833. https://doi.org/10.1080/14606 925.2018.1518111

Daguitan F, Lehohla P, Mwangi C, et al (2019a) The current state of our data and knowledge. In: Global Environment Outlook Healthy People. UN Environment, Nairobi, Kenya

Daguitan F, Mwangi C, Tan MG, et al (2019b) Future Data and Knowledge Needs. In: Global Environment Outlook - GEO-6: Healthy Planet, Healthy People. UN Environment, Nairobi, Kenya

Danylo O, Moorthy I, Sturn T, et al (2018) The Picture Pile tool for rapid image assessment: a demonstration using Hurricane Matthew. ISPRS Annals of Photogrammetry, remote sensing and spatial information sciences IV-4:27-32. https://doi.org/10.5194/ isprs-annals-IV-4-27-2018

Datashift (2017) Using citizen-generated data to monitor the SDGs. A tool for the GPSDD data revolution roadmaps toolkit. Available at: https://www.data4sdgs.org/resources/making-use-citizen-gener ated-data

Dickinson JL, Zuckerberg B, Bonter DN (2010) Citizen science as an ecological research tool: Challenges and benefits. Annu Rev Ecol Evol Syst 41:149-172. https://doi.org/10.1146/annurevecolsys-102209-144636

Dunning C, Kalow J (2016) SDG Indicators: Serious Gaps Abound in Data Availability. Available at: https://www.cgdev.org/blog/ sdg-indicators-serious-gaps-abound-data-availability

Eitzel MV, Cappadonna JL, Santos-Lang C et al (2017) Citizen science terminology matters: exploring key terms. Citizen Sci 2:1. https://doi.org/10.5334/cstp.96

Flückiger Y, Seth N (2016) SDG indicators need crowdsourcing. Nature 531:448-448. https://doi.org/10.1038/531448c

Fritz S, See L, Carlson T et al (2019) Citizen science and the United Nations Sustainable Development Goals. Nat Sustain 2:922930. https://doi.org/10.1038/s41893-019-0390-3

GEO (2017) Earth Observations 2030 Agenda for Sustainable Development, V1.1. Japan Aerospace Exploration Agency (JAXA) on behalf of GEO under the EO4SDG Initiative. Available at: https ://www.earthobservations.org/documents/publications/20170 3_geo_eo_for_2030_agenda.pdf

GEO (2018) GEO Highlights 2016-2017, Impact Focused, Results Driven. Available at: https://www.earthobservations.org/docum ents/publications/2018_geo_highlights_report.pdf

Givoni M (2016) Between micro mappers and missing maps: Digital humanitarianism and the politics of material participation in disaster response. Environ Plan D 34:1025-1043. https://doi. org/10.1177/0263775816652899 
Gray J, Lämmerhirt D, Bounegru L (2016) Changing What Counts. How can Citizen-Generated Data and Civil Society be used as an Advocacy Tool to Change Official Data Collection. Available at: https://civicus.org/thedatashift/wp-content/uploads/2016/03/ changing-what-counts-2.pdf

Hicks A, Barclay J, Chilvers J et al (2019) Global mapping of citizen science projects for disaster risk reduction. Front Earth Sci 7:226. https://doi.org/10.3389/feart.2019.00226

HOTOSM (2016) Mapping our impact. Annual Report. Available at: https://www.hotosm.org/downloads/2016-Annual-Report.pdf

Howe J (2006) The rise of crowdsourcing. Wired Magazine 14:1-4

Howitt C (2019) Personal communication. Sustainable Coastlines, Litter Intelligence Program

IAEG Secretariat (2014) A World that counts. mobilising the data revolution for sustainable development. Available at: https:// www.undatarevolution.org/wp-content/uploads/2014/11/AWorld-That-Counts.pdf

ISWGHS (2019) Achieving the full potential of household surveys in the SDG Era. Available at: https://unstats.un.org/unsd/statc om/50th-session/documents/BG-Item4c-ISWGHS-E.pdf

Jambeck JR, Geyer R, Wilcox C et al (2015) Plastic waste inputs from land into the ocean. Science 347:768-771. https://doi. org/10.1126/science. 1260352

Jensen D, Campbell J (2019) Discussion Paper. the case for a digital ecosystem for the environment: bringing together data, algorithms and insights for sustainable development. Available at: https://un-spbf.org/wp-content/uploads/2019/03/Digital-Ecosy stem-final.pdf

Kelman I (2017) Linking disaster risk reduction, climate change, and the sustainable development goals. Disaster Prev Manage 26:254258. https://doi.org/10.1108/DPM-02-2017-0043

Kullenberg C, Kasperowski D (2016) What is citizen science? - A scientometric meta-analysis. PLoS ONE 11:e0147152. https://doi. org/10.1371/journal.pone.0147152

Lämmerhirt D, Gray J, Venturini T, Meunier A (2018) Advancing sustainability together? Citizen-generated Data and the sustainable development goals. Available at: https://www.data4sdgs. org/sites/default/files/services_files/Advancing\%2520Sustainabil ity\%2520Together\%2520CGD\%2520Report_1.pdf

Liu H-Y, Schneider P, Haugen R, Vogt M (2019) Performance assessment of a low-cost PM2.5 sensor for a near four-month period in Oslo, Norway. Atmosphere 10:41. https://doi.org/10.3390/atmos 10020041

MacDonald C (2012) Understanding participatory action research: a qualitative resarch methodology option. Can J Action Res 13:34-50

Minghini M, Delucchi L, Sarretta A et al (2017) Collaborative mapping response to disasters through OpenStreetMap: the case of the 2016 Italian earthquake. Geoingegneria Ambientale e Mineraria 151:21-26

Mooney P, Minghini M (2017) A review of OpenStreetMap data. In: Foody GM, See L, Fritz S, et al. (eds) Mapping and the Citizen Sensor. Ubiquity Press, London, UK, pp 37-59

Nov O, Arazy O, Anderson D (2010) Crowdsourcing for science: understanding and enhancing SciSourcing contribution. ACM Press, New York City

OECD (2017) Earth observation for decision-making. Available at: https://www.oecd.org/environment/indicators-modelling-outlo oks/Earth_Observation_for_Decision_Making.pdf

Ormel H, Kok M, Kane S et al (2019) Salaried and voluntary community health workers: exploring how incentives and expectation gaps influence motivation. Human Res Health 17:59. https://doi. org/10.1186/s12960-019-0387-z

Palmer JRB, Brocklehurst M, Tyson E et al (2018) Global mosquito alert. In: Hecker S, Haklay M, Bowser A, et al. (eds) Citizen
Science innovation in open science, society and policy. UCL Press, London UK

Quinlivan L, Chapman D, Sullivan T (2019) Validating citizen science monitoring of ambient water quality for the United Nations sustainable development goals. Sci Total Environ 13(4):2-55. https ://doi.org/10.1016/j.scitotenv.2019.134255

Rose NL, Turner SD, Goldsmith B et al (2016) Quality control in public participation assessments of water quality: the OPAL Water Survey. BMC Ecol 16:14. https://doi.org/10.1186/s1289 8-016-0063-2

SDSN TReNDS (2019) Counting on The World to Act. A Roadmap for Governments to Achieve Modern Data Systems for Sustainable Development.

See L, Fritz S, Dias E et al (2016) Supporting Earth-Observation Calibration and Validation: a new generation of tools for crowdsourcing and citizen science. IEEE Geosci Magaz 4:38-50. https://doi. org/10.1109/MGRS.2015.2498840

Shirk JL, Ballard HL, Wilderman CC et al (2012) Public participation in scientific research: A framework for deliberate design. Ecol Soc 17:29. https://doi.org/10.5751/ES-04705-170229

Sieber RE, Haklay M (2015) The epistemology(s) of volunteered geographic information: a critique. Geogra Environ 2:122-136. https ://doi.org/10.1002/geo2.10

Tyson E, Bowser A, Palmer J et al (2018) Global Mosquito Alert: Building citizen science capacity for surveillance and control of disease-vector mosquitoes. Wilson Center, Washington, D.C., USA

UN (n.d.) Tier Classification for Global SDG Indicators. Available at: https://unstats.un.org/sdgs/iaeg-sdgs/tier-classification/

UN (2015) A/RES/70/1 UN General Assembly Transforming our World: the 2030 Agenda for Sustainable Development. Seventieth session of the General Assembly on 25 Sept 2015

UN (2017) A/RES/71/313 Work of the Statistical Commission pertaining to the 2030 Agenda for Sustainable Development. Seventyfirst session of the General Assembly on 6 July 2015

UN (2018) Sustainable Development Goals Report 2018. Available at: https://unstats.un.org/sdgs/files/report/2018/TheSustainableD evelopmentGoalsReport2018-EN.pdf

UN (2019a) The Sustainable Development Goals Report. 2019. Available at: https://unstats.un.org/sdgs/report/2019/

UN (2019b) Ninth Meeting of the Inter-Agency and Expert Group on the Sustainable Development Goal Indicators 26-28 March 2019. United Nations Economic and Social Commission for Western Asia, Beirut, Lebanon

UN (2019c) SDG Indicator changes (15 October 2018 and onward). Available at: https://unstats.un.org/sdgs/files/List_of_changes_ since_15_Oct_2018.pdf

UN (2019d) SDG Indicators. Metadata repository. Available at: https ://unstats.un.org/sdgs/metadata/

UN Environment (2019) Measuring Progress: Towards Achieving the Environmental Dimension of the SDGs. Available at: https:// wedocs.unep.org/handle/20.500.11822/27627

UNEP-WCMC, IUCN, NGS (2018) Protected Planet Report 2018. Tracking Progress Towards Global Targets for Protected Areas. Available at: https://livereport.protectedplanet.net/pdf/Protected_ Planet_Report_2018.pdf

USAID (2015) African Strategies for Health: Community Health Worker Incentives: Lessons Learned and Best Practices from Madagascar. Available at: https://www.msh.org/sites/default/ files/chw_incentives.lessons_and_best_practices_for_madagascar .december_23.pdf

USAID (2017) 10,000 Community health volunteers receive equipment from USAID's community capacity for health program. Available at: https://www.usaid.gov/Madagascar/press-relea 
ses/10000-community-health-volunteers-receive-equipment-usaid $\% \mathrm{E} 2 \% 80 \% 99 \mathrm{~s}$

Vincent S (2018) Status Review of the Updated Rural Access Index (RAI). Draft Final Report, London, UK

Wehn U, Almomani A (2019) Incentives and barriers for participation in community-based environmental monitoring and information systems: A critical analysis and integration of the literature. Environ Sci Policy 101:341-357. https://doi.org/10.1016/j.envsc i.2019.09.002

Wehn U, McCarthy S, Lanfranchi V, Tapsell S (2015) Citizen observatories as facilitators of change in water governance? Experiences from three European cases. Environ Eng Manag J 14:2073-2086

\section{Affiliations}

West S, Pateman R (2017) How could citizen science support the Sustainable Development Goals? Stockholm: SEI. Available from: https://www.sei.org/mediamanager/documents/Publications/SEI2017-PB-citizen-science-sdgs.pdf

Publisher's Note Springer Nature remains neutral with regard to jurisdictional claims in published maps and institutional affiliations.

\section{Dilek Fraisl ${ }^{1,2}$ (1) - Jillian Campbell ${ }^{3} \cdot$ Linda See $^{1} \cdot$ Uta Wehn $^{4} \cdot$ Jessica Wardlaw ${ }^{5} \cdot$ Margaret Gold $^{6} \cdot$ Inian Moorthy $^{1}$. Rosa Arias $^{7}$. Jaume Piera ${ }^{8} \cdot$ Jessica L. Oliver ${ }^{9,10}$. Joan Masó ${ }^{11} \cdot$ Marianne Penker $^{2} \cdot$ Steffen Fritz $^{1}$}

Jillian Campbell

campbell7@un.org

Uta Wehn

u.wehn@un-ihe.org

Jessica Wardlaw

j.wardlaw@nhm.ac.uk

Margaret Gold

mg@margaretgold.co.uk

Rosa Arias

rarias@bifi.es

Jaume Piera

jpiera@icm.csic.es

Jessica L. Oliver

jl.oliver@hdr.qut.edu.au

Joan Masó

joan.maso@uab.cat

Marianne Penker

marianne.penker@boku.ac.at

1 Ecosystem Services and Management Program, International Institute for Applied Systems Analysis (IIASA), Schlossplatz 1, Laxenburg, Austria

2 University of Natural Resources and Life Sciences (BOKU), Vienna, Austria
3 UN Environment Programme (UNEP), Nairobi, Kenya

4 IHE Delft Institute for Water Education, Westvest 7, 2611 AX Delft, The Netherlands

5 Natural History Museum, Cromwell Road, South Kensington, London SW7 5BD, UK

6 European Citizen Science Association (ECSA), Museum für Naturkunde Berlin, Invalidenstraße 43, 10115 Berlin, Germany

7 Ibercivis Foundation, Campus Río Ebro, Edificio I+D, C/Mariano Esquillor, s/n, 50018 Zaragoza, Spain

8 Institute of Marine Sciences (ICM-CSIC), Passeig Marítim de la Barceloneta 37-49, 08003 Barcelona, Spain

9 School of Electrical Engineering and Computer Science, Queensland University of Technology, 2 George St, Brisbane, QLD 4000, Australia

10 Australian Citizen Science Association (ACSA), University of Sydney, City Road, Darlington NSW, Camperdown 2006, Australia

11 Grumets Research Group. CREAF. Edifici C, Universitat Autònoma de Barcelona, 08193 Bellaterra, Catalonia, Spain 